\title{
A Measure of the Ability of a Region to Provide Clean Water Yiming $\mathrm{Li}^{1, \mathrm{a}}$ \\ ${ }^{1}$ North China Electric Power University, Baoding 071000, China \\ a849403872@qq.com
}

Keywords: water resource, WRCC

\begin{abstract}
Water resources issue is a big problem faced by the mankind. In this paper, we establish an evaluation model based on the water resource carrying index formula. In the whole process of modeling, we fully consider the social economy, water resources and the ecological environment, and have tested each model.
\end{abstract}

\section{Introduction}

Water, the magical combination between one oxygen and two hydrogen atoms, is crucial for all kinds of life existing on the earth. Without water, we would cease to live continued. However, water scarcity problem has become projecting.

Water shortages have affected all continents, according to the United Nations; 1.6 billion people experience water scarcity. Otherwise, the fact that water use has been growing at twice the rate of population suggests that more and more region will face the water scarcity. Therefore, in order to prevent us from heading a thirsty planet, addressing the world's water problem is of significance.

Here, we establish a model to measure the ability of a region to provide clean water in view of the dynamic factors that affect both supply and demand.

\section{Assumptions and Justifications}

- There are hundreds of indexes, and we cannot collect and analyze all of them in limited time. Hence, we choose some typical indexes for evaluation.

- The data we have collected is sufficient and accurate.

- Rainfall guaranteed rate in Shandong Province is $75 \%$.

- We set $\mathrm{C}=20$ if $\mathrm{C}>20$ in this paper

\section{Different definition of water resources carrying capacity}

Since the concept of water resources carrying capacity was come up with by United Nations Educational, Scientific and Cultural Organization (UNESCO) [1], academia around the world countries has a variety of expressions on it.

Based on the analysis of those concept, we can define the water resources carrying capacity as a regional water resources system which under the condition of certain social economic sustainable development, premising on the coordination of the healthy development of the ecological environment and the sustainable of the social economy.

\section{Practical significance of water resources carrying capacity}

In order to provide theoretical and technical support to the regional economic development strategy, we research on the water resources carrying capacity which means that the layout of the future economic development should be based on the condition of the regional water resources, in other words, deciding demand by support[1].

The paragraph above is the elaboration of WRCC's significance, aiming to achieve the harmonious development among the social economy, water resources and the ecological 
environment. The framework of it is as shown in Figure 1.

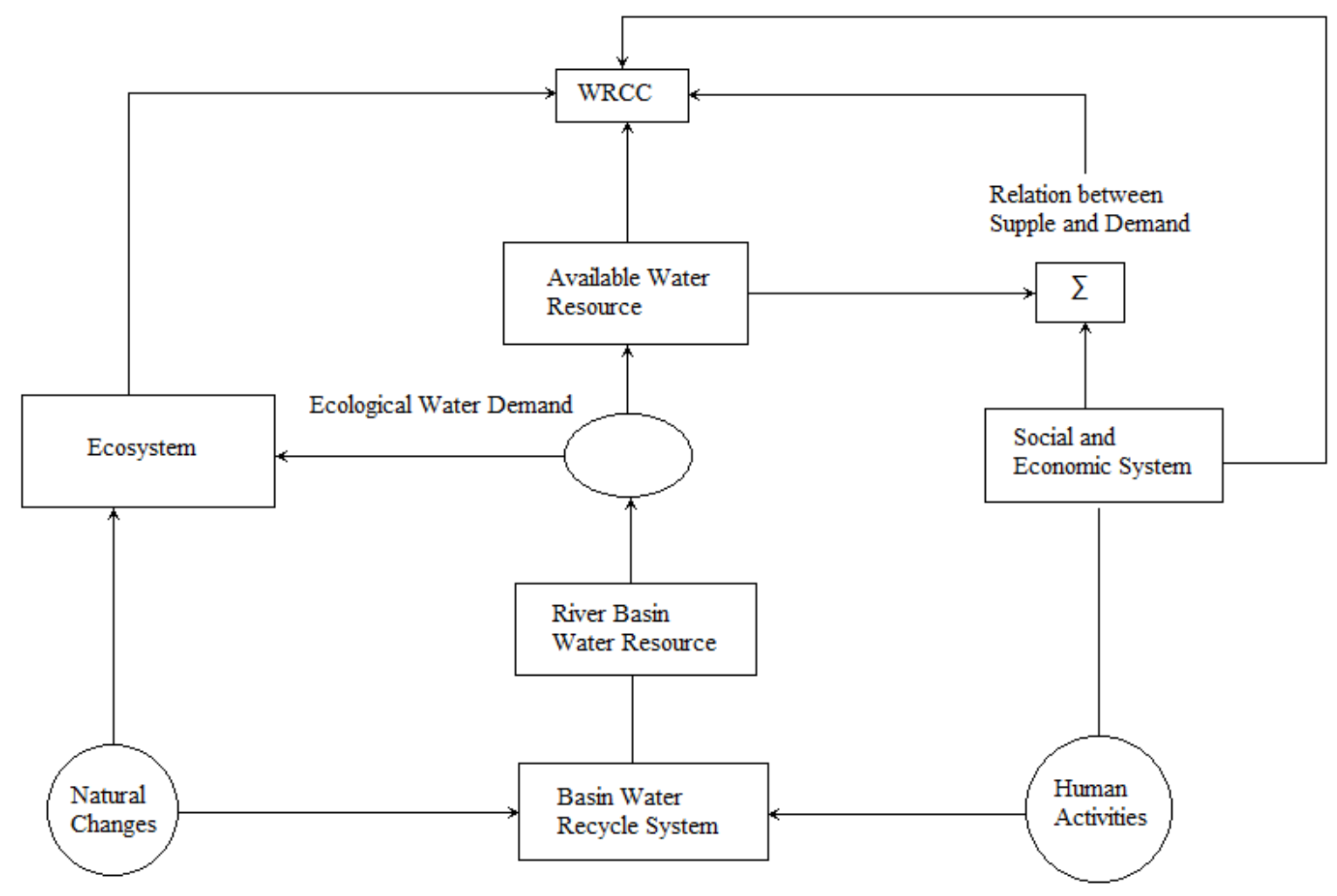

Figure 1. The framework of WRCC

\section{WRCC Assessment Model}

\subsection{Introduction}

Since water resources carrying capacity can judge the relation between water supply and demand, it's reasonable to assess the ability of a region to provide clean water to meet the needs of its population by analysis WRCC.

Chinese Academy of Science has taken abundant researches on water resources carrying capacity. One of them is studying the water shortage problem on Jingjinji Region located in Haihe River valley by a certain formulation[2], which can be a reference for us to build our model.

\subsection{Analysis}

In the previous research, the physical meaning of WRCC that the precipitation, population and agricultural irrigation area determine the needs of water was proposed. Taking the dynamic nature of the factors that affect both supply and demand into account, we choose the population, GDP, total water resources and precipitation to help construct a WRCC assessment model to distinguish the ability of a region to provide clean water [2].

\subsection{Solution and Results}

Referring to the formula that was given and connecting with WRCC's definition, we collect 180 countries' related data to get the load factors rank of water resources. The formula for describing WRCC is shown as follows:

$$
\boldsymbol{C}=\boldsymbol{K} \sqrt{P \bullet G} / \boldsymbol{W}
$$

Where $C$ is water loading index for describing WRCC, $K$ is a coefficient related with the precipitation, $P$ is population, $G$ means GDP and $W$ means total water resources.

Then we get the load factors rank of water resources that is shown in Table 1. 
Table 1. The load factors rank of water resources

\begin{tabular}{lcll}
\hline Rank & The Value of $C$ & $\begin{array}{l}\text { Water Utilization } \\
\text { Level }\end{array}$ & Evaluation \\
\hline I & $>10$ & Extremely high & Very difficult to develop \\
II & $5 \sim 10$ & High & Difficult to develop \\
III & $2 \sim 5$ & Middle & Moderately difficult to develop \\
IV & $1 \sim 2$ & Low & Easy to develop \\
V & $<1$ & Extremely low & Very easy to develop \\
\hline
\end{tabular}

The larger value of $C$ is, the more difficult is to develop water resources. Hence, if a region wants to have a better water resources carrying capacity, the value of $C$ must be smaller.

\subsection{Model Testing}

Following the solution above, we collect 180 countries' related data and the country and river basin rankings on baseline water stress [3]. It takes us 2 steps to finish.

Step 1: Using MATLAB on formula (1) to calculate the value of $C$.

Step 2: Disposing the data that we calculated and compare the model results with the rankings we found. For one thing, according to Table 2, we classify those countries into 5 phases by the value of $C$. For another thing, we calculate the mean of $C$ value in every phase that was listed in the ranking tabulation we found as a reference. The results of them are described in Figure 2.

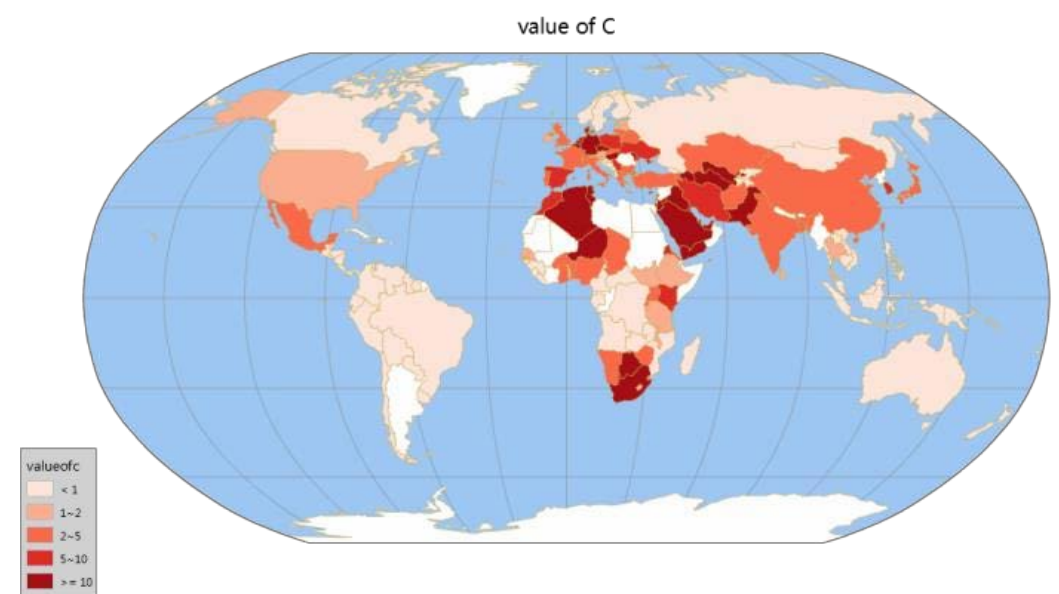

Figure 2. The comparison of model results with reference

\section{Conclusion}

By analyzing Figure 2, it is obvious that the result we get from the model we build is analogous to the reference, which means the reliability of our model. What's more, it is because of the different indexes we using that brings about deviation.

\section{References}

[1] Qingchun Duan, Changming Liu, Xiaonan Chen, Wenhua Liu, Hongxing Zheng. Regional Water Resources Carrying Capacity Concept and Research Methods.[J] Geographical Science, 2010, 65 (1): 82-89

[2] Zhiming Feng, Dengwei Liu, Water supply and demand balance and water resources bearing capacity in Jingjinji region. [J] Journal of Natural Resources, 2006, 21 (5): 690- 694

[3] World Resources Institute. www.wri.org.

[4] Zhu Yizhong, Xia Jun, Tan Ge. Prediction and evaluation of water resources carrying capacity in northwest region of China [J]. resources science, 2003,04:43-48 